\title{
A CONSTRUÇÃO DA HISTÓRIA E A LEGITIMAÇÃO DA MEMÓRIA NO PROCESSO DE PRESERVAÇÃO DO CASARÃO PAU PRETO
}

CARLOS GUSTAVO NÓBREGA DE JESUS

Universidade Estadual de Campinas (Unicamp), Campinas, São Paulo, Brasil

Doutor em História. Pesquisador Colaborador da Unicamp - Instituto de Filosofia e RECEBIDO Ciências Humanas. E-mail: cnobregadejesus@yahoo.com.br 24/07/2015

DOI

APROVADO

http://dx.doi.org/10.11606/issn.1980-4466.v0i20p9-35

$26 / 11 / 2015$ 


\section{A CONSTRUÇÃO DA HISTÓRIA E A LEGITIMAÇÃO DA MEMÓRIA NO PROCESSO DE PRESERVAÇÃ̃O DO CASARÃO PAU PRETO \\ CARLOS GUSTAVO NÓBREGA DE JESUS}

\section{RESUMO}

O seguinte artigo tem o intuito de discutir a questão do patrimônio cultural e suas relações com as políticas públicas de preservação e legitimação da memória. Para tanto, partiu-se do estudo do processo de tombamento de um bem edificado localizado na cidade de Indaiatuba, interior do estado de São Paulo, construído entre 1810 e 1812, denominado Casarão Pau Preto. A partir de escritos de memorialistas locais e laudos técnicos de especialistas, buscou-se levantar algumas evidências da relação da conservação do imóvel com as políticas públicas de preservação patrimonial e com o empenho de construção de uma memória e legitimação da história da cidade, em torno da consagração de tal patrimônio histórico.

PALAVRAS-CHAVE

Patrimônio cultural. Políticas públicas. Casarão Pau Preto. 


\title{
THE CONSTRUCTION OF HISTORY AND THE LEGITIMIZATION OF MEMORY IN THE PRESERVATION PROCESS OF CASARÃO PAU PRETO \\ CARLOS GUSTAVO NÓBREGA DE JESUS
}

\begin{abstract}
The following article aims to discuss the issue of cultural heritage and its relations with public policies for preservation and the legitimacy of memory. The foundation for the article was the study of the listing as a heritage site of Casarão Pau Preto, a building located at Indaiatuba, state of Sao Paulo, and built between 1810 and 1812. Based on writings from local memorialists and technical reports by experts, we attempted to raise evidences of the relationship between the estate conservation, the public policies for heritage preservation and the effort to build a collective memory and legitimize the city's history due to the listing as a heritage site.
\end{abstract}

KEYWORDS

Cultural heritage. Public policies. Casarão Pau Preto. 


\section{INTRODUÇÃO}

Neste artigo será discutido o processo de preservação e tombamento de um bem edificado (1984-2008), localizado na cidade Indaiatuba, interior do estado de São Paulo, e sua relação com as políticas públicas nacionais de proteção do patrimônio histórico daquele momento.

O bem, denominado Casarão Pau Preto, construído entre 1810 e 1812 na cidade de Indaiatuba, distante 90 quilômetros da cidade de São Paulo, foi casa paroquial e depois sede da fazenda que levava o mesmo nome. Do ponto de vista arquitetônico, pode ser caracterizado por uma mistura de estilos e técnicas construtivas, como a taipa de mão, de pilão e "alvenaria inglesa".

Indaiatuba é hoje um abastado centro urbano e industrial da região metropolitana de Campinas; no entanto, suas origens remontam à segunda metade do século XVIII, como uma região de parada na estrada de Itu para Vila de São Carlos (Campinas), o que contribuiu para que se tornasse um pequeno polo populacional, formando-se, no começo do século XIX, como um pequeno bairro de Itu.

1. No levantamento técnico sobre a situação do Casarão do Pau Preto, elaborado em 6 de março de 2013, o Arquiteto Charles Fernandes (2013, p. 1) definiu desta forma a técnica "alvenaria inglesa" empregada no Casarão Pau Preto: "No começo do século XX (o Casarão Pau-Preto) recebeu uma edificação adjacente para beneficiamento de café, que acompanhou as tecnologias trazidas pela ferrovia, com alvenaria de tijolos aparentes de barro maciços e queimados, assentados por argamassa, tecnicamente chamada de 'alvenaria inglesa'." 
Nesses tempos, Itu estava prestes a se tornar a "Vila mais rica de toda a província de São Paulo, destacando-se na importante participação política e na economia, em função dos negócios de exportação de açúcar para a Europa" (ALVES, 2007, p. 12). Localizada na região conhecida como o "quadrilátero do açúcar", território entre Campinas, Sorocaba, Jundiaí e Mogi Mirim, passou a produzir, depois da metade do século XVIII, açúcar em grande escala. ${ }^{2}$

Em 1813, o bairro de Itu, conhecido por Cocais, teve sua capela curada (CARVALHO, 2004, p. 37-38) e, em 9 de dezembro de 1830, foi feita Freguesia por Decreto do Imperador - situação que possibilitou a nomeação de Juízes de Paz, bem como vereadores que serviriam na Câmara Municipal de Itu. Só em 24 de março de 1859 foi elevada à "Vila, isto é, categoria de 'Munícipio', através da Lei n. 12 do Presidente da Província de São Paulo", tendo sido "procedidas no dia 3 de julho as eleições de vereadores para a Câmara Municipal de Indaiatuba" (SAMPAIO, 1998, p. 44-51).

Foi nesse momento que a produção açucareira começou a ser substituída pelo café no planalto paulista:

[...] 1846-1847 é, certamente, o ano mais importante, $\mathrm{o}$ ano decisivo para a cultura canavieira. Os agricultores do hinterland de Santos, a partir de então, resolvem abandonar o cultivo da cana-de-açúcar para se dedicarem ao café. O 'quadrilátero do açúcar' vai transformar-se em zona cafeeira. O café plantado em 1846-1847 produzirá, em 1850-1851, ano em que ultrapassa, em volume, a exportação de açúcar pela barreira de Cubatão. Estranha coincidência! No ano de maior exportação de açúcar também foram formados grandes cafezais, e daí a pouco produzirão tanto, que o açúcar passará para o segundo lugar nas exportações de Santos. (PETRONE, 1968, p. 162)

No entanto, especificamente na região do "quadrilátero do açúcar", tal mudança ocorreu algumas décadas mais tarde, pois:

2. "Quadrilátero do açúcar" foi a denominação dada para a região entre Piracicaba, Sorocaba, Jundiaí e Mogi Guaçu que, depois da metade do século XVIII (PETRONE, 1968, p. 24-53), entre o fim da extração do ouro nas Gerais e o começo da produção cafeeira no Rio de Janeiro e São Paulo, passou a produzir açúcar em grande escala, a ponto se tornar a principal base econômica do país na época. (ELLIS JUNIOR, 1979, p. 104). A produção açucareira, com sua lavoura de cana e seus engenhos, foi a responsável por introduzir a plantation no planalto paulista. 
[...] a implantação da lavoura cafeeira ocorreu de forma desigual nas vilas do oeste paulista, até a sexta década do século XIX. Enquanto declinava a produção de açúcar e o canavial cedia espaço ao cafezal em municípios como Campinas e Rio Claro, o número de engenhos e o consequente aumento da produção de açúcar ampliava-se em municípios como Itu, Piracicaba, Capivari e Mogi-Mirim (MELO, 2006, p. 76)

Desta forma, seguindo o modelo das demais cidades da região, Indaiatuba teve sua produção direcionada para os campos de café nas três últimas décadas do século XIX, o que fez com que os cafeicultores vissem, nesse momento, a necessidade de criar uma alternativa para escoar sua produção. Com tal intuito, foi idealizada em 1870 a Companhia Ytuana de Estradas de Ferro, que se originou de uma concessão outorgada em 1870, destinada a fazer a ligação entre Itu e a São Paulo Railway, em Jundiaí. Para tanto, construíram-se vários ramais que foram responsáveis por boa parte da distribuição da produção cafeeira nas décadas de 1870 e 1880 .

As duas primeiras linhas construídas pela Companhia passavam por Indaiatuba: a Jundiaí-Pimenta (Indaiatuba), inaugurada em 1872, e a Pimenta-Itu, criada em 1873. Esta última "abriu o ramal de Piracicaba, partindo de Itaici, atingindo Capivari, a partir de 1875, Rio das Pedras em 1876 e Piracicaba em 1879" (ANNUNZIATTA, 2003, p. 4). Especialistas no tema destacam a importância estratégica da Estação de Itaici em Indaiatuba, pois "era um ponto de parada de onde abria uma chave para o ramal de Piracicaba", além de ser "um ponto de distribuição e de ligação entre o interior do estado de São Paulo e suas regiões". Desse modo, como era "uma estação de união, ligava a região de Sorocaba a Campinas, Piracicaba e Jundiaí, atualmente as maiores regiões do interior paulista" (ANUNZIATA, 2003, p. 4 e 8).

Sendo assim, pode-se notar que, historicamente, Indaiatuba esteve, desde o final do século XVIII, em uma região estratégica da província de São Paulo. Tal condição colaborou para que ali se concentrasse uma significativa parcela populacional, tornando-se foco de fixação de moradias. No entanto, a maior parte de tais testemunhos edificados da história da cidade se perdeu, perdurando alguns poucos remanescentes, entre eles o Casarão Pau Preto (PAIVA, 2002, p. 6). Essa situação conferiu-lhe o status 
de uma das construções históricas mais reconhecidas pela comunidade local. Por isso, no começo dos anos 1980, iniciou-se um movimento popular, liderado pelo jornalista Sérgio Squilanti, em prol da preservação do bem, já que parte da Tulha, feita no final do século XIX em alvenaria inglesa, para abrigar a máquina de beneficiar café, tinha sido derrubada em virtude da especulação imobiliária.

A primeira mobilização popular ocorreu em 1982, organizando-se passeatas, reuniões, e protestos na imprensa - o que resultou no decreto 2.394, de 20 de abril de 1982, do prefeito Clain Ferrari, declarando o bem edificado como de utilidade pública, a fim de ser adquirido, mediante desapropriação, e sua área de terreno de 9.810 metros quadrados, para ser utilizada para "instalação de museu histórico, centro cultural e parque de lazer" (CARVALHO, 1984, p. 11). Entretanto, o próprio prefeito Clain Ferrari revogou o decreto em 14 de dezembro de 1982, o que fez a comunidade continuar a se mobilizar, por meio de projeções de filmes, exposições e passeatas.

Muito provavelmente em consequência de tal reivindicação popular, em 24 de fevereiro de 1983, o novo prefeito, José Carlos Tonin, pelo decreto número 2.615, novamente declarou a edificação como de utilidade pública. No entanto, nesse momento, a área considerada foi de 4.500 metros quadrados.

Em 1984, o prefeito anunciou o início de uma recuperação do Casarão, que foi executada pelo Departamento de Obras da Prefeitura, com supervisão de uma comissão da comunidade nomeada pelo prefeito (Comissão de Participação do Projeto Cultural do Casarão Pau Preto), que contava com nomes como o do memorialista local Nilson Cardoso Carvalho, o fotógrafo Antônio da Cunha Penna, o engenheiro José Carlos Bicudo, o advogado Fernando Stein, entre outros.

Recuperado, o Casarão foi simbolicamente entregue à população da cidade em 9 de dezembro de 1985, dia de comemoração do aniversário de Indaiatuba, sendo tombado como Patrimônio Histórico do Município muito mais tarde, em dezembro de 2008 (Decreto Municipal 10.108). Atualmente, concentra-se, no local, a sede do Museu Municipal e da Fundação PróMemória de Indaiatuba.

O laudo técnico que subsidiou a abertura do processo de tombamento se apoiou na argumentação de que as edificações do Casarão conservam características que a recomendam "[...] a título perene, a ser mantido como 
amostra significativa da evolução histórica de Indaiatuba. Suas características construtivas justificam a conservação como objeto de pesquisas de História da Técnica" (PAIVA, 2002, p. 7).

No entanto, acredita-se que há outras questões que foram preponderantes para a preservação da construção histórica, que vai além da sua riqueza arquitetônica e dialoga com a construção da identidade dos moradores da cidade e com o desejo de um grupo consolidar uma memória e uma história específica para o município. Propõe-se, então, investigar como foi a construção desse processo e qual é a relação dessa operação com a sacralização do Casarão Pau Preto como um patrimônio de relevante valor histórico e principal lugar da memória da cidade de Indaiatuba.

\section{PRESERVAÇÃO E A CONSTRUÇÃO DE UM IDEAL BANDEIRISTA}

Dentre as várias iniciativas do movimento em prol da preservação do Casarão Pau Preto, pode-se destacar a estratégia de se forjar o fato de que a edificação fez parte do ciclo bandeirista. Tal ideia teve, entre seus percursores, o memorialista Nilson Cardoso Carvalho que, no propósito de apoiar o movimento de preservação do bem, produziu em 1984 o livreto Arquitetura de taipa: um dos últimos exemplares em Indaiatuba. Nessa obra, o autor apoiou-se em uma aproximação um tanto artificial ao comparar a planta da edificação de Indaiatuba com o modelo bandeirista proposto por Luis Saia.

É possível levantar a hipótese de que as ligações afetivas do memorialista com a causa de preservação do bem o fez cometer alguns equívocos do ponto de vista da pesquisa histórica. Em virtude disso, principalmente, a sua prática investigativa se distanciou de uma operação historiográfica e, na maior parte das vezes, tomou os documentos como fontes objetivas do passado, deixando, justamente, de levar em conta o que Michel de Certeau chamou de "não dito", ou seja, as informações que estão nas entrelinhas de tais fontes (CERTEAU, 200o, p.67). ${ }^{3}$

\footnotetext{
3. A historiadora Ana Maria Camargo (2004, p. 12-13) escreveu que ele "frequentou regularmente o Arquivo do Estado de São Paulo, transcrevendo todos os documentos relacionados com Indaiatuba. Dos arquivos eclesiásticos das Cúrias Metropolitanas de São Paulo e de Campinas trouxe subsídios para o conhecimento não apenas da antiga paróquia de Nossa Senhora da Candelária, centro originário de Indaiatuba, mas também de inúmeros aspectos da vida comunitária da época, profundamente marcada pela presença da Igreja."
} 
Tal prática é comumente encontrada nos escritos dos memorialistas, nos quais experiências pessoais se misturam às escritas do passado e emoções se confundem à interpretação literal das fontes, iniciativas que os levam a uma busca quase ingênua de uma suposta objetividade, calcada não só nas fontes, mas também em fatos, datas e nomes, fugindo, assim, dos princípios fundamentais da historiografia no que se refere ao tratamento documental. Por outro lado, deve-se levar em conta que, mesmo com tais limitações, esses escritos se aproximam de narrativas históricas, pois, ainda que contenham uma parcialidade interpretativa, não são totalmente formados pela ficção, apresentando conexões com a memória a partir das lembranças e da experiência vivida.

No entanto, diante de todas as situações que contribuíram para se cunhar um perfil arquitetônico artificial para o bem, talvez nenhuma tenha sido mais forte que o intuito de se alinhar ao discurso das políticas públicas de preservação patrimonial vigentes na época. Assim, pode-se afirmar que ao salientar o fato de o Casarão ter sua planta semelhante ao estilo bandeirista e datar de um período próximo aos "últimos exemplares", consagrado por Luis Saia (CARVALHO, 1984, p. 7), Nilson Carvalho buscou dar legitimidade ao bem a partir de um critério já oficializado pelo Serviço do Patrimônio Histórico e Artístico Nacional (Sphan) - na época, o principal órgão de preservação do país. ${ }^{4}$

A política de preservação patrimonial brasileira baseou-se, desde a criação do órgão, em 1937, na tentativa de objetivar o que era subjetivo, ou seja, criar um critério universal que definiria o que deveria ser tombado ou não, baseado em características arquitetônicas específicas dos bens edificados.

\footnotetext{
4. A ideia de um órgão de proteção ao patrimônio histórico nacional começou a surgir quando Gustavo Capanema, então responsável pelo Ministério da Educação e Saúde (MES), convidou Mário de Andrade para criar o anteprojeto de um órgão de proteção ao patrimônio histórico nacional, nomeado previamente de Span. No entanto, segundo Silvana Rubino (2002, p. 148), o caráter plural das propostas de Mário fez com que o texto do seu anteprojeto fosse alterado, ficando por responsabilidade de Rodrigo Melo Franco a redação do Decreto número 25 de 1937, que criou o Sphan. Rodrigo Melo Franco de Andrade dirigiu a instituição até 1969, quando morreu. Em 1946 o órgão se tornou Departamento do Patrimônio Histórico e Artístico Nacional (DPHAN). Em 1970 foi transformado em Instituto do Patrimônio Histórico e Artístico Nacional (Iphan), em 1979 voltou a se chamar Sphan, tendo a Fundação Nacional Pró-Memória como seu órgão executivo. Em 1990 tornou-se Instituto Brasileiro do Patrimônio Cultural (IBPC), para em 1994 voltar a ser denominado Instituto do Patrimônio Histórico e Artístico Nacional (Iphan), como se chama atualmente.
} 
Nesse sentido, o arquiteto Lucio Costa, chefe da Divisão de Estudos e Tombamentos (o principal departamento de ordem técnica do Sphan), foi o principal responsável por concretizar tal proposta, sedimentando, também, na época, um modelo historiográfico para os estudos sobre a história da

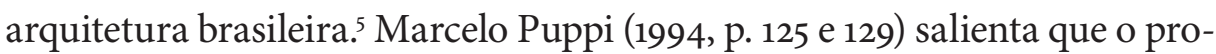
pósito principal de tal modelo se baseava no fato de levantar os equívocos e aprofundar estudos da casa colonial brasileira. Tal situação levou-o a defender a tese de que qualquer estudo da arquitetura brasileira devia recuar até o século XVII para definir um parâmetro (PUPPI, 1994, p. 127-128).

Essa proposta tornou-se marcante ao longo do tempo, a ponto de tomar conta do próprio imaginário nacional, uma vez que até hoje há uma nítida preferência em se preservar um bem de estilo arquitetônico colonial, conforme se pode constatar ao examinarmos a lista dos bens edificados tombados pelo Iphan. ${ }^{6}$

Desta forma, os critérios utilizados por Lucio Costa na Divisão de Estudos e Tombamentos do Sphan rapidamente ganharam ar de oficialidade, sendo apropriados nas diversas Delegacias Regionais no Brasil. Entre elas a de São Paulo, com Mário de Andrade e Luis Saia, local que encontrou terreno fértil, pois ia ao encontro do projeto político e ideológico cunhado pela elite paulista nos anos 1920, que aproveitou o momento de discussão acerca de projetos para nação para tentar legitimar uma leitura própria do passado brasileiro, baseada no discurso de que a história da nação era a história de São Paulo. Tal tese concentrava-se na tentativa de forjar a identidade do povo paulista a partir da imagem do bandeirante e do mestiço (RODRIGUES, 2000, p. 21-22). ․ Foi na concretização de tal discurso que se destacou a figura de Luis Saia, discípulo e herdeiro de Mário de Andrade, que passou a dirigir a regional de São Paulo em 1939 e seguiu no cargo até 1975, quando faleceu (MAYUMI, 2005, p. 16). Saia foi o primeiro

\footnotetext{
5. Marcelo Puppi (1994, p. 124) afirma que a adesão dos pesquisadores ao modelo histórico de Lucio Costa deve-se ao fato de dar uma visão global da arquitetura "[...] desobrigando os arquitetos de analisar e compreender o passado".

6. Conferir o texto "Bens tombados e registrados" na página institucional do Iphan. Disponível em: http://portal.iphan.gov.br/portal/montarPaginaSecao.do?id=17733\&sigla=Institucional\&reto rno=paginaInstitucional. Acesso em 14 nov. 2014.

7. O maior exemplo dessa proposta é a montagem histórica do Museu Paulista feita por Affonso d'Escragnolle Taunay a partir de 1917, na qual um Museu de História Natural foi transformado em um local de consagração de uma interpretação ilustrada da nação à paulista (BREFE, 2005, p. 118-119).
} 
a estigmatizar os traços da arquitetura paulista a partir do estilo colonial que denominou "casa bandeirista" (termo criado por ele para a casa rural paulista), dividindo seu estilo arquitetônico em duas vertentes, a pura e a tardia, o que deixava evidente um juízo de valor em tal definição, pois julgava pura aquela construção que se aproximasse do estilo colonial luso brasileiro do século XVII e XVIII.

Segundo Lia Mayumi (2005, p. 36), a tese do "tipo arquitetônico puro" e o desejo modernista de valorizar as raízes culturais paulistas miscigenadas, legitimou "restaurações de casas bandeiristas orientadas para a recuperação da imagem 'pura', autorizando a destruição de elementos arquitetônicos desconformes com o cânone arquitetônico" e removendo "dos exemplares, sempre que possível, os traços da 'decadência' social, cultural e estilística".

A maior evidência de que a chamada "Academia Sphan" solidificou suas propostas são os trabalhos da geração seguinte, que pensou o patrimônio histórico, principalmente paulista, como, por exemplo, Carlos Lemos e Ernani Silva Bruno. Ambos, mesmo com algumas considerações diferenciadas, conservaram boa parte das premissas da dita "fase heroica" do órgão (LONDRES, 2005, p. 81-130), como a valorização da arquitetura colonial e a crença no diferencial paulista advindo da miscigenação, principalmente do branco com o indígena: "[...] entende-se por bandeirista a designação das atividades do mameluco em suas próprias plagas" (LEMOS, 1999, p. 12). Da mesma forma, Julio Katinsky, em A casa bandeirista (1979), designou a expressão "tradição bandeirista", que teria abarcado "também as edificações de inspiração bandeirista construídas a partir da metade do século XVIII" (ZANETTINI, 2005, p. 74) e não somente as ditas edificações "puras", privilegiadas por Saia, mais próximas do século XVII. Por isso, ao rol das 16 casas bandeiristas propostas por Saia, Katinsky adicionou mais 13, que corresponderiam à "tradição bandeirista", abrindo caminho, assim, para toda aproximação e apropriação que podiam ser feitas de tal modelo - situação que daria legitimidade para o processo de preservação e restauração de qualquer bem que pudesse dialogar, de alguma forma, com esse perfil arquitetônico.

8. As características arquitetônicas dos bens que tiveram intervenções a partir de 1939 e depois aqueles que foram tombados até 1979 deixam claro esse critério. (MAYUMI, 2005, p. 15-18). 
Por isso, a ideia de um programa de "tradição bandeirista" tornouse um relevante argumento para aqueles que defendiam o estilo colonial como principal representante da arquitetura de São Paulo, ainda mais se pensarmos que, na realidade, a maioria das cidades paulistas foi "fundada ou profundamente reconstruída entre o século XIX e XX", sobrando muito pouco da arquitetura essencialmente colonial no estado (MARINS, 2008b, p. 151). Assim, para se encaixar no modelo excludente das políticas públicas estatais que privilegiavam o bem arquitetônico colonial, a saída era exatamente cunhar a ideia do estilo arquitetônico de tradição bandeirista, que se estenderia para um bem edificado que ia além, temporal e geograficamente, "do cinturão caipira de chácaras ao redor de São Paulo, e seguia no vale do rio Tietê na rota dos desbravadores e colonizadores" (ZANETTINI, 2005, p. 74).

A luta pela preservação do Casarão Pau Preto apoiou-se em tal discurso, abarcado pela hipótese de que suas características coloniais seriam o motivo para que fosse preservado e outras edificações históricas da cidade não. Tal situação nos possibilita afirmar que não foi descabida, do ponto de vista político, a estratégia utilizada por Nilson Carvalho de adequar a sua proposta de preservação àquela vigente na época e praticada por órgãos oficiais, ou seja, valorizar a preservação das moradas de tradição colonial, especificamente bandeirista, nem que para isso tivesse que abrir mão de um estilo peculiar da edificação, que tinha como sua marca a representação de, pelo menos, mais de um estilo arquitetônico (PAIVA, 2003, p. 7). Obviamente, essa situação não reduzia o partido arquitetônico do Casarão Preto à tradição colonial bandeirista.

Interessa salientar, nesse sentido, que tal estratégia (no mínimo ambígua do ponto de vista arquitetônico e histórico) obteve êxito, e a maior evidência disso é o parecer técnico de tombamento do Casarão (CLP26/2002), feito 18 anos depois, por Celso Lago Paiva. Mesmo tendo chamado a atenção para as evidências da mistura de técnicas construtivas e para os diferentes estilos arquitetônicos presentes no bem edificado (situação que, para ele, inclusive possibilitaria inserir a cidade de Indaiatuba no circuito das cidades históricas e turísticas), o técnico se aproximou do discurso de Nilson Carvalho para concluir que a preservação do imóvel se justificava, dentre outros apontamentos, pelo fato de filiar-se "ao partido colonial, que 
caracteriza as mais antigas edificações de uso civil na região paulista dos séculos XVIII e XIX" (PAIVA, 2002, p. 5-6; CLP-26/2002).

O posicionamento técnico de Celso Lago Paiva é um tanto contraditório, pois tem o cuidado de não mencionar o termo "bandeirista", pois sabia que seria inapropriado para tal edificação, mas nem por isso deixou de definir o Casarão Pau Preto a partir do estilo "colonial do século XVIII". (Idem). Na verdade, tal ambiguidade deixa patente o interesse em legitimar a relevância histórica da edificação a partir dos critérios privilegiados pelos órgãos de proteção nacional e apropriados por Nilson Carvalho.

Tal hipótese ganha maior credibilidade se atentarmos para os demais laudos técnicos de bens considerados por Paiva passíveis de preservação. No laudo de outro bem edificado, tombado posteriormente em Indaiatuba, a Fazenda Engenho d'Água, mesmo depois de descrever algumas características que a distanciavam do estilo bandeirista, ele apresentou uma saída para aproximar a edificação do clássico partido colonial das moradas paulistas: "As características primitivas dessa construção (datada por mim de 1755 +/15 anos) prevalecem, fazendo dela exemplar conservador, quase bandeirista no sentido atribuído por Katinsky" (PAIVA, 2002, p. 10; CLP-15/2002, grifo nosso). ${ }^{9}$ Em outro parecer técnico, desta vez de uma edificação contemporânea ao Casarão Pau Preto, a Casa Número Um (CLP-22/2002), ${ }^{10}$ nota-se que o técnico, mesmo conhecendo as singularidades da casa bandeirista, em alguns momentos também reduz a arquitetura colonial a tal terminologia consagrada por Saia. Segundo suas palavras, a Casa Número Um, "de características semelhantes ao Casarão, se particulariza por filiar-se ao partido bandeirista, que caracteriza as mais antigas edificações de uso civil na região paulista do século XIX" (PAIVA, 2002, p. 4 e p.6; CLP-22/2002). Pode-se considerar essa conclusão um tanto equivocada, ainda mais ao se levar em conta outro laudo pericial a respeito do mesmo bem:

9. No título de um artigo escrito por Paiva em 1998 a respeito da Fazenda, ele deixa clara não só sua aproximação com o discurso legitimador do modelo colonial, como também o seu conhecimento a respeito da diferença entre o termo bandeirista e tradição bandeirista: "Engenho d’Água: uma casa de tradição bandeirista em Indaiatuba, estado de São Paulo".

10. Celso Lago Paiva (2002, p. 4-5, CLP-22/2002) data a Casa Número Um em 1830 +/- 15 anos, afirmando que é a "segunda mais antiga edificação residencial urbana sobrevivente em Indaiatuba, sendo posterior apenas ao chamado Casarão Pau Preto". 
O interesse pela preservação da Casa Número 1 recorre não somente no seu aspecto exemplar ainda hoje de uma residência típica da ocupação urbana do estado de São Paulo, desde o início do século XIX, quando as casas localizadas próximas à matriz, em várias cidades (Itu, Sorocaba, Campinas, mas também Amparo, sem esquecer inúmeros exemplos no Vale do Paraíba, como em São Luiz do Paraitinga) possuíam as seguintes características: a) Ocupação frontal e lateral do terreno em relação ao lote e ao calçamento; b) Pequena elevação do pavimento da casa em relação à rua, com introdução de grande porta monumental por quase toda a extensão do pé direito do vestíbulo de entrada; c) Distribuição dos ambientes em três "lanços" distribuídos da rua para os fundos, sendo sala e quarto principais (primeiro lanço); alcovas e depósitos (segundo lanço) e cozinha e dispensas (terceiro lanço); d) Telhado com cumeeira principal e alinhada, paralelamente, à rua do ingresso; e) Utilização de técnicas construtivas leves, como a taipa de mão, para a configuração das divisórias e paredes frontais; f) Estabelecimento de um quintal no restante posterior de serviços, geralmente delimitado por alvenarias pesadas, como a taipa de pilão, para distinção do lote em relação aos vizinhos; neste quintal se instalavam "casinhas" sanitárias, a criação de víveres, a cozinha suja em uma edícula precária, o pequeno jardim com pomar g) Os caixilhos são ainda de manufatura elementar de carpintaria, mas as janelas já apresentam folhas de vedação e em breve futuro, ainda no século XIX, serão instaladas guilhotinas com requadros de vidros. Todas essas características construtivas, formais, morfológicas e espaciais estão presentes na Casa Número 1, definitivamente um exemplo do modo de morar dos habitantes de Indaiatuba que superava o modelo, limitado, das construções rurais paulistas do século XVIII (TOGNON, 2015, p. 9)

Assim, não é descabido afirmar que Celso Lago Paiva amparou seu argumento na tese de Katinsky de "herança bandeirista" para tentar encaixar a 
Casa Número 1, a Fazenda Engenho d’Água e o Casarão Pau Preto em tal proposta, pois acreditava que dessa forma poderia ter uma maior probabilidade de sucesso na preservação de tais bens. Mas, ao mesmo tempo em que a definição alargava o espectro das casas bandeiristas, ainda se apoiava na tríade capela-varanda-quarto de hóspedes (ZANETTINI, 2005, p. 84), atributos que, de acordo com o próprio Paiva, não se encaixava no estilo do Casarão: "As características primitivas dessa construção (data por mim de 1820 +/- 10 anos) prevalecem, fazendo dela exemplar conservador, ainda que nada dela corresponda à faixa posterior de cômodos, com sua varanda típica". Tal situação à primeira vista dificultaria rotular o estilo da edificação como "essencialmente colonial paulista", mas não para Paiva, que, de forma surpreendente, completava o raciocínio afirmando que esse "despojamento formal da edificação reflete a sobriedade da vida dos proprietários rurais do período colonial paulista" (PAIVA, 2002, p. 8; CLP-26/2002).

Desta forma, bandeirista, tradição bandeirista, morada rural ou urbana, pouco importava a delicada, mas relevante diferença entre os termos (ANDRADE; COSTA, 2011, p. 194); o importante era dar ênfase a um suposto estilo arquitetônico colonial anterior ao da era do café, que não por acaso era o privilegiado nas políticas de preservação do país. Isso corrobora a hipótese de que essa aproximação forçada fez parte de uma estratégia de discurso construída e utilizada tanto no laudo do Casarão, como por Nilson Carvalho no seu livreto, para legitimar a proposta de preservação do bem.

Todo esse esforço de adequação a um modelo aceito nas políticas oficiais de preservação do patrimônio cultural edificado não pôde esconder a artificialidade de tal aproximação, que fica clara ao se atentar para os escritos do próprio Luis Saia, a partir dos quais se nota nitidamente a desconformidade entre o estilo arquitetônico da casa bandeirista e do Casarão Pau Preto, a começar pela localização temporal de edificações bandeirista, que para Saia se estendia ao século XVIII e não ao XIX, como assevera Nilson. Ele chega até a mencionar as casas do século XIX, mas como uma herança dos mineiros, que, ao ser:

liquidada a exploração do ouro de lavagem, iniciaram um movimento para São Paulo, trazendo consigo as características das construções montanhesas [...] Nada comparável, entretanto, que pudesse indicar uma base sólida para a organização da 
coletividade paulista [...] E, nada, portanto, equiparável ao que ocorrera no período bandeirista (1611-1727) (SAIA, 1978, p. 47).

Além disso, para Saia, as taipas do século XIX não tinham os mesmos cuidados que as dos séculos XVII e XVIII:

A taipa das construções do século seguinte não só apresenta os mesmos cuidados, como pelo contrário indica descuido na fatura propriamente dita e ainda no uso de quadro desse processo de edificar. Deve-se, realmente, supor que as condições desfavoráveis de economia e mobilidade demográfica, que afligiram os séculos XVIII e XIX, vieram criar circunstâncias prejudiciais ao aprendizado das técnicas correntes (SAIA, 1978, p. 85)

Saia também repudiava as comparações entre plantas, como fizera Nilson Cardoso:

Cumpre ter em vista que a análise deste tipo de residência não se deve prender unicamente à planta; para considerar mais completamente o funcionamento, a importância especial em mesmo a concepção do conjunto, torna-se preciso estudar a aplicação desse esquema em três dimensões (SAIA, 1978, p. 71)

Mesmo que despidas de qualquer má intenção, tais aproximações soam como uma tentativa forçada de encaixar a linguagem arquitetônica de toda construção histórica nos parâmetros das características coloniais bandeiristas. Nesse caso, deve-se concordar com Paulo César Garcez Marins (2008b, p. 112) que deixa claro que as tentativas de adequar as moradas erguidas a partir da metade do século XVIII ao bandeirismo são um sério caso de anacronismo, "já que a maior parte delas estava ligada à produção de açúcar ou às repercussões do tropeirismo e não mais às expedições sertanistas".

Mas no Casarão de Indaiatuba, como em outros bens de diferentes regiões do estado, tal adequação não ocorreu somente por meio do discurso, mas também da prática. A maior prova disso é que, na primeira obra de "restauro" do bem, em 1984, houve a preocupação em substituir janelas com vidraças, características do século XIX, por janelas protegidas por 
grades de seção retangular, particularidades das mais antigas moradas paulistas (MARINS, 2008b, p. 117). A estratégia utilizada por Nilson Carvalho para buscar a preservação do Casarão revela que não há como se pensar em um pesquisador, seja acadêmico ou memorialista, fora do seu lugar social e de seu tempo histórico (CERTEAU, 200o, p. 66), que, especificamente nesse caso, estava pautado por uma prática e um discurso legitimador de que qualquer preservação deveria seguir os ideais abarcados na arquitetura colonial, produto da mestiçagem, que em São Paulo se configurou nas casas bandeiristas edificadas por mãos mamelucas. Nem que para isso precisasse fazer desparecer seus diversos traços arquitetônicos originais.

Não se pode negar que devido a essa perspicácia, muito mais política do que técnica, legitimada pelos laudos, Nilson Carvalho e seu grupo ganharam a luta pela preservação do bem. No entanto, deve-se salientar que não foi apenas esse discurso que contribuiu para o sucesso de tal empreitada.

\section{CASARÃO PAU PRETO E A GÊNESE DA CIDADE}

Para fortalecer sua proposta, o grupo que lutava pela preservação do Casarão buscou o peso da tradição, ou melhor, como bem salientou Hobsbawm (1984, p. 15), da “invenção da tradição". Dessa forma, tentou legitimar o bem como o marco zero da constituição da cidade:

Localizado no ponto de origem do pequeno povoado, o Casarão assistiu à sua história, desde o pequeno aglomerado de moradores até a próspera cidade industrial que é hoje Indaiatuba, sendo lamentável assistirmos à sua deterioração, ou demolição, sem que a população saiba que o Casarão não é apenas uma "velharia" - mas um testemunho concreto da história e da arquitetura da cidade (CARVALHO, 1984, p. 12)

Essa versão da história era vinculada diretamente ao surgimento do primeiro conglomerado urbano de Indaiatuba no largo da Matriz, no qual o Casarão, ao lado da Igreja, supostamente era um dos seus protagonistas. A justificativa perpassava duas questões principais: primeiro, por sua arquitetura bandeirista (a arquitetura de alvenaria inglesa da tulha era pouco mencionada), depois, como lugar da memória que melhor representava as origens da cidade (com maior destaque do que a própria Matriz), 
despertando, assim, o sentimento de identidade e pertença da população, conforme transparece claramente no texto de Nilson Carvalho:

Arquitetura de Taipa - um dos últimos exemplares em Indaiatuba foi feito para chamar a atenção da população de Indaiatuba para a importância do Casarão da Fazenda do Pau Preto e atingiu seus objetivos. Distribuído em um momento em que o prédio era destruído, contribuiu para engrossar o movimento para sua preservação que avolumava na cidade. Este movimento teve seu ponto alto na apresentação do audiovisual (com foto de Antonio da Cunha Penna e sonorização e narração de Renato Carramenha) para uma plateia repleta na Câmara Municipal [...] A apresentação terminava tal e qual esse folheto com um veemente apelo para preservação deste prédio, testemunho das origens de Indaiatuba. O efeito deste audiovisual foi imediato: ao final da apresentação o prefeito José Carlos Tonin anunciou a desapropriação que fez vibrar a plateia e foi uma festa (CARVALHO, 1984, p. 13-14).

Discurso que também foi legitimado quando acolhido pelo técnico responsável pelo parecer, que abriu o processo de tombamento do bem, no qual afirmou que o Casarão Pau Preto tratava-se "da mais antiga edificação residencial urbana sobrevivente em Indaiatuba [...] remanescente e original dos núcleos primitivos de colonização urbana do município (centro histórico)" (PAIVA, 2002, p. 2). Na verdade, essa versão a respeito da origem de Indaiatuba, a partir de seu centro urbano, no qual o Casarão era protagonista, refletia uma leitura específica do passado, que acabou sendo generalizada e se fixou na memória coletiva local, inclusive norteando trabalhos referentes à cidade a partir de então. Entre eles, pode-se citar a coletânea $O$ ofício de compartilhar histórias (2001), na qual a jornalista Ana Lígia Scachetti reproduziu tal hipótese sobre a origem da cidade em artigos com títulos sugestivos, como por exemplo: "A verdadeira história do Casarão Pau Preto", "A história de Joaquim Emígdio de Campos Bicudo" e "Igreja Matriz marca o princípio de Indaiatuba".

Tal versão apareceu até mesmo em produções de historiadores, como Indaiatuba: história e memórias da antiga Freguesia de Cocaes e dos anos 
que sucederam desde então, o trabalho mais atual sobre a cidade, de 2011, de Adriana Koyama. Nas suas primeiras páginas ela até propõe uma nova leitura das origens de Indaiatuba:

[...] não seguiremos esses mesmos caminhos. Iremos em busca de outras questões, de outros fios de pesquisa, de indicações sobre as forças que moviam a vida de homens e mulheres desses sertões, desde os primeiros documentos referentes a Indaiatuba, no século XVIII. Encontraremos a Igreja e Pedro Gonçalves [...], mas a narrativa construída será um pouco diferente dessa que temos ouvido e lido (KOYAMA, 2011, p. 16).

No entanto, ao se aprofundar na obra, nota-se que, se não "seguiu os mesmos caminhos" dos primeiros memorialistas, tampouco foi além das últimas propostas a respeito da construção da história de Indaiatuba, compartilhando da leitura de seu pai, Nilson Carvalho, acerca da origem da cidade:

O largo e a Igreja da Candelária têm em sua arquitetura a marca histórica das formas da vida cotidiana e civil do século XIX, nossa mais antiga dimensão urbana. Nele vemos a chamada Casa número um, também do século XIX, na esquina da matriz, com seu muro de taipa original [...] A poucos metros de caminhada, deparamo-nos com o Casarão do Pau Preto, essa antiga chácara urbana que já pertenceu ao pároco da Candelária e à família Bicudo, e ainda guarda em seus jardins traços dos quintais de antigamente (KOYAMA, 2011, p. 71).

Por meio de uma breve pesquisa da produção sobre a história de Indaiatuba, foram encontradas outras hipóteses em relação à sua origem, muitas delas anteriores àquela levantada por Nilson, como, por exemplo, a de Azevedo Marques e Nardy Filho, que relata a lenda religiosa de que José da Costa encontrou uma imagem de Nossa Senhora da Candelária e nesse local teria erigido uma capelinha. Ou a do Dr. Scyllas Sampaio, que em 1978 defendeu a ideia de que a vila se localizava no córrego Votura, mas, devido a uma epidemia de varíola, a população buscou outro local, onde se desenvolveu a 
cidade - o atual centro histórico de Indaiatuba (SAMPAIO, 1998, p. 39, 41 e 42). Em um artigo de 1958, Antonio Zoppi afirmou que Indaiatuba surgiu na parada para descanso de animais, entre Itu e Campinas (ZOPPI, 1998, p. 55-57).

Estudos como de Silvane Rodrigues Leite Alves e de Leonardo Godoy buscaram na documentação existente as primeiras evidências do povoado para tratar das origens de Indaiatuba. Silvane (2007, p. 11-12) se apoiou em um circular do governador da Província, Martins Lobo de Saldanha, datado de 1777 (que segundo ela foi uma das "primeiras citações referentes ao povoado de Indaiatuba”), para afirmar:

A cidade de Indaiatuba surgiu por volta de 1730-1740, em terras pertencentes à Vila de Itu. Inicialmente uma parada de tropeiros, que se dirigiam das regiões de Sorocaba e Itu para Campinas, tendo o povoado a denominação inicial de Votura, posteriormente substituído por Cocais e finalmente Indaiatuba - nome originário da junção de dois termos da língua tupi-guarani: "indaiá" que designa um tipo de palmeira, e "tuba" que equivale a "grande quantidade, muito". Portanto, Indaiatuba, tem por significado "muitos indaiás, local abundante em indaiás.”

Leonardo Godoy (2014, p. 19), ao estudar Antônio Pires de Campos, o PaiPira, bandeirante de Itaici, ${ }^{11}$ salienta que no Inventário de Cristóvão Diniz, um dos fundadores de Itu, em 1650, já era possível delimitar um pedaço de terra chamada Endaiativa, nos famosos campos do porto de Pirapitingui, local de saída de bandeiras do então "Boca do Sertão", como era conhecido Itu entre os séculos XVII e XVIII. Além disso, com base em documentação cartorial, complementa:

No fim do século, XVII, em 1699 Pires de Campos, acompanhando seu sogro, deixou Curitiba com 550 Carijós, herança da tia para Salvador Jorge Velho. Esse exército precisava de um lugar grande e estruturado. Parece que a paragem do Ajapy já era lugar conhecido por hospedar esses índios, porém

11. No seu estudo Leonardo Godoy afirma que foi o Pai-Pira quem descobriu a Serra dos Martírios, local rico em ouro (hoje São Geraldo do Araguaia, no Pará), povoou Cuiabá, além de participar de várias bandeiras, inclusive com Anhanguera. 
como Itaici [...] Em Itaici os rios Jundiaí, Piraí e Votura eram caminhos via canoa. Por terra havia picadas, como as que tinham origem do Peabiru de Sorocaba e o caminho de São Paulo via Santana do Parnaíba: estas seguiam para a estrada do Anhanguera em direção a Goiás. Foi por aí que começou a aparecer a futura Indaiatuba, como pouso para os viajantes e tropeiros (GODOY, 2014, p. 14 e p.17).

De acordo com Godoy, Itaici era um relevante povoado naquele momento, podendo ser o mais antigo registro de povoação do que depois viria a ser a cidade de Indaiatuba. Mas, deve-se salientar que tal localização é um tanto distante do dito centro histórico representado pela Igreja e pelo Casarão Pau Preto, espaço privilegiado por Nilson Cardoso como marco zero de Indaiatuba. Nota-se que as documentações utilizadas por Silvane e Godoy foram desprezadas por aqueles que buscavam no referido centro histórico e no Casarão a representação do mito fundador de Indaiatuba. É evidente que levar em conta essas diferentes versões não ajudariam na concretização do discurso positivista de Nilson Carvalho e seu grupo, apoiado na invenção de tradições marcadas por uma história contínua e retilínea de fatos muito bem encadeados - situação propícia para se forjar um passado único e glorioso para a Indaiatuba e para os indaiatubanos.

Nesse sentido, um último ponto pode ser ainda salientado para justificar o empenho na preservação do Casarão do Pau Preto, diferenciando-o dos demais bens de semelhante valor histórico da cidade, que não tiveram a mesma sorte de serem preservados, ${ }^{12}$ nas palavras do próprio Nilson Carvalho: "O casarão é propriedade da família Bicuda há mais de cem anos e é elogiável como conservaram com o mínimo de interferência até os nossos dias" (CARVALHO, 1984, p. 10-11). A família Bicudo é legitimada como uma das pioneiras na constituição do conglomerado social e urbano escolhido por Nilson como ponto de origem de Indaiatuba. Para o memo-

\footnotetext{
12. A Fazenda Engenho d'Água, a sede de fazenda mais antiga existente em Indaiatuba e base da economia açucareira da cidade (KOYAMA, 2011, p. 31), mesmo tombada por decreto municipal, nunca foi alvo de intervenção de restauro ou conservação preventiva. $\mathrm{O}$ mesmo pode-se falar dos demais casarões do Largo da Candelária, contemporâneos do Pau Preto, que foram, na sua maioria, derrubados e os que sobraram hoje estão em ruínas (KOYAMA, 2011, p. 81).
} 
rialista, Joaquim Gonçalves Bicudo e seu irmão Pedro Gonçalves Meira são nomes de destaque em tal empreitada:

Em 1794 Ludovico Manoel de Oliveira e demais herdeiros de Antonio Nunes de Oliveira venderam para Joaquin Gonçalves Bicudo "húm Citio na paragem chamada Indayatuba, Bairro de Jundiahi”. Esta escritura, lavrada no cartório de Itu, é um importante documento, pois todos esses herdeiros foram seguidamente recenseados nas vizinhanças de Joaquim Gonçalves Bicudo e de seu irmão Pedro Gonçalves Meira e sua presença é um sinal seguro para localização de Indaiatuba nas listas anuais de recenseamento" (CARVALHO, 2009, nota 1, p. 23).

Adriana Koyama (2011, p. 40-42) também deixa claro o papel de destaque da família na construção da cidade, conforme apontado por Nilson Carvalho: Sabemos, pelos registros da Cúria Metropolitana, que Pedro Gonçalves Meira construiu uma igreja, que é hoje a matriz Nossa Senhora da Candelária [...] Reencontramos então aqui a indicação de que a consagração das terras da Nossa Senhora marca a fundação da cidade, pois a Igreja não tinha só um papel religioso, mas também um importante papel político e social [...].

Assim, nada mais óbvio que se sacralizasse como símbolo da constituição da cidade o local e a casa em que morou por anos uma família tradicional de Indaiatuba. Deve-se destacar que tal iniciativa ganhou credibilidade não somente pelo discurso construído e legitimado por Nilson Carvalho e seu grupo, mas também em virtude do contexto histórico específico dos meados dos anos 1980, quando parcelas da população acreditavam que precisariam "proteger" a memória responsável pela constituição de uma identidade "ameaçada" pela onda de migrantes das mais diferentes regiões do Brasil, os quais eram atraídos para Indaiatuba pelo enriquecimento e crescimento da região metropolitana de Campinas. Nesse caso, pode-se dizer que a luta pela preservação do Casarão Pau Preto foi além de uma preocupação preservacionista; na verdade, foi um subsídio para se cunhar 
uma origem para a cidade, calcada na invenção de uma tradição e baseada em uma leitura conservadora, que privilegiava os nomes de famílias tradicionais socialmente e economicamente destacadas na constituição da história de um povo. Além disso, tal posicionamento foi totalmente excludente, a ponto de não levar em consideração a diversidade de sujeitos históricos que contribuíram para escrever a história da cidade, como, por exemplo, os escravos, operários e principalmente os imigrantes e migrantes que povoaram Indaiatuba desde sua origem.

A partir disso, não fica difícil asseverar que o tombamento ou salvaguarda são práticas subjetivas e políticas, sempre refletindo os interesses de um grupo e à mercê de um conhecimento técnico especializado, que pode variar de acordo com linhas teóricas e interesses diversos.

\section{CONSIDERAÇÕES FINAIS}

A partir de tal discussão, nota-se que salvar o Casarão foi uma forma de proteger uma memória e salvar uma versão da história da constituição da cidade, cunhada por um grupo que estava de acordo com as posturas preservacionistas da época, resumidas ao fato de que o bem passível de preservação é aquele de origem colonial e/ou que foram pertencentes, preferencialmente, a nomes da elite sociopolítica e católica de uma determinada época.

Tal postura salvou muitas igrejas, sedes de fazendas e casarões coloniais - edificações vitais para a história e a memória do nosso país. Por outro lado, contribuiu para o desaparecimento de vários terreiros, senzalas, casas populares de alvenaria, bairros operários, sinagogas, mesquitas e representantes da cultura imaterial popular de um país tão pouco conhecido, ou, o que é pior, que não se quer conhecer. Não seria o momento de se privilegiar os vários sentidos da memória, começando por acabar com a hierarquia de valores, rompendo com a ideia de uma única história dita oficial, buscando olhar para novas documentações, para grupos sociais diversos e temporalidades variadas?

Deve-se destacar que é elogiável a luta pela preservação do Casarão Pau Preto, empreendida por parte da população, que começou em 1980 e culminou no seu tombamento em 2008. Sem isso, ter-se-ia perdido um relevante exemplar de edificação histórica, tão cara à constituição da cidade. Mas, se por um lado tal postura possibilitou a preservação do Casarão, por 
outro, também contribuiu para enterrar suas múltiplas histórias, representadas por várias técnicas construtivas presentes no bem edificado, que foram reduzidas ou violentamente transformadas, em benefício da leitura de um grupo específico, apresentada como única capaz de ser legitimadora e oficial. A energia empreendida na tentativa de forjar uma leitura artificial do passado seria muito mais relevante para a história da cidade se fosse direcionada para salientar o ecletismo arquitetônico do complexo histórico em questão. Com isso, inéditas histórias de Indaiatuba emergiriam, trazendo consigo, em maior amplitude, novos indícios da constituição da cidade - situação positiva em todos os sentidos, até para aqueles que acreditam que o caminho para despertar o sentimento de pertença seja ressaltar um passado perfeito, recheado de glórias. A relevância da cidade no escoamento da produção agrícola, por meio de suas linhas ferroviárias, poderia ser tema de pesquisas facilmente elaboradas a partir do interesse em estudar com maior veemência a alvenaria inglesa da tulha do Casarão Pau Preto. O mesmo pode-se dizer da produção cafeeira da região, das técnicas de beneficiamento de café dos fins do XIX e, principalmente, da participação da mão de obra imigrante e escrava, não só nas construções das paredes de tijolos e taipas, respectivamente, mas também, na constituição da identidade da cidade. Se a mesma preocupação dispensada ao Casarão Pau Preto fosse direcionada aos outros casarões de arquitetura eclética da cidade, Indaiatuba também seria vista como local relevante, juntamente com Itu, na economia cafeeira de São Paulo.

No entanto, olhar para essas multiplicidades de sentidos, até mesmo no que se refere às técnicas construtivas utilizadas no Brasil, não é muito bem visto por aqueles que cuidam do nosso patrimônio cultural, pois sob a aparência de discurso democrático esconde-se um posicionamento altamente conservador que se coloca totalmente contra qualquer reavaliação de um passado consagrado que possa mexer com as vaidades e verdades absolutas construídas a partir de interesses de grupos específicos.

Por outro lado, tal postura se coloca contra o perfil da nossa Carta Constitucional de 1988, dita cidadã, que deixa claro a relevância das contribuições de diversas culturas não homogêneas para a construção de um Brasil multifacetado. Essa situação conduz a um questionamento a respeito não somente da falta de iniciativa ou da negligência da proteção ou não das 
edificações e práticas culturais que nunca foram privilegiadas, como também induz a lançar novos olhares para os bens já preservados, desconfiando de leituras pré-formatadas ou baseadas nas tradições culturais forjadas por grupos que se sentem predestinados, do ponto de vista técnico, econômico e social, para poder decidir, de forma parcial, como se deve escrever o passado. Novos sujeitos devem ser ouvidos e novas histórias devem ser contadas e o historiador não pode mais negligenciar isso.

\section{REFERÊNCIAS}

ALVES, Silvane Rodrigues Leite. A instrução pública em Indaiatuba: 1840-193o. Contribuição para a história da educação brasileira. Campinas, 2007. 200 f. Dissertação (Mestrado em Educação), Universidade Estadual de Campinas-UNICAMP.

ANDRADE, Francisco de Carvalho Dias; COSTA, Eduardo. Arquitetura bandeirista na Serra do Itapeti: um caso interessante para o estudo da arquitetura colonial paulista. In: VII Encontro de História da Arte da Unicamp. 2011. Campinas. Anais do VII Encontro de História da Arte da Unicamp. 2011. p. 192-199.

ANUNZIATA, Henrique. Parecer Técnico HA-01/2003 Relevância cultural e recomendação de tombamento e conservação a título permanente da Estação Itaici, Indaiatuba, São Paulo. In: FUNDAÇÃO PRÓ-MEMÓRIA DE INDAIATUBA. Processo de tombamento n.11/2012. Processo de Tombamento de nove bens de valor histórico e arquitetônico da cidade de Indaiatuba. (Acervo arquivístico do órgão).

BREFE, Ana Cláudia Fonseca. O Museu Paulista: Affonso de Taunay e a memória nacional. São Paulo: Editora Unesp/Museu Paulista, 2005.

BRUNO, Ernani Silva. Equipamento da casa bandeirista segundo os antigos testamentos e inventários. São Paulo: Departamento do Patrimônio Histórico, 1977.

CAMARGO, Ana Maria. Apresentação. In: Carvalho, Nilson Cardoso de. A Paróquia de Nossa Senhora da Candelária. Indaiatuba: Fundação Pró-Memória, 2004. p. 11-14.

CARVALHO, Adriana Koyama. Indaiatuba: história e memórias da antiga Freguesia de Cocaes e dos anos que a sucederam desde então. Campinas: Komedi, 2001.

CARVALHO, Nilson Cardoso. Cronologia indaiatubana. Indaiatuba: Fundação Pró-Memória/ Ottoni, 2009.

Arquitetura em taipa: um dos últimos exemplares em Indaiatuba. Indaiatuba: s/d, 1984.

CERTEAU, Michel. A escrita da história. 2. ed. Rio de Janeiro: Forense Universitária, 2000.

ELLIS JÚNIOR, Alfredo. A economia paulista no século XVIII. São Paulo: Academia Brasileira de Letras, 1979.

FERNANDES, Charles. Levantamento técnico a respeito da atual situação do complexo histórico Casarão Pau Preto. Indaiatuba: Fundação Pró-Memória, 2013. 
FONSECA, Maria Cecília Londres. O patrimônio em processo: trajetória da política federal de preservação no Brasil. 2. ed. Rio de Janeiro: Editora UFRJ/IPHAN, 2005.

GODOY, Leonardo. Relatório de pesquisa - Pai Pira: o bandeirante de Itaici. Indaiatuba, 2014. (no prelo).

HOBSBAWM, E.; TERRANCE, R. A invenção das tradições. Rio de Janeiro: Paz e Terra, 1984.

KATINSKY, Julio Roberto. A casa bandeirista: nascimento e reconhecimento da arte em São Paulo. Tese (Doutorado). Faculdade de Arquitetura e Urbanismo, Universidade de São Paulo, São Paulo, 1973.

LEMOS, Carlo A. C. Casa paulista: história das moradias anteriores ao ecletismo trazido pelo café. São Paulo: Edusp, 1999.

MARINS, Paulo César Garcez. A vida cotidiana dos paulistas: moradias, alimentação, indumentária. In: SETÚBAL, Maria Alice (coord.). Terra paulista: histórias, arte e costumes. Modos de vida dos paulistas: identidades, famílias e espaços domésticos. São Paulo: CENPEC/IMESP, 2008a. p. 89-185.

Trajetórias de preservação do patrimônio cultural paulista. In: SETÚBAL, Maria Alice (coord.). Terra paulista: trajetórias contemporâneas. São Paulo: CENPEC/IMESP, 2008b. p. 135-165.

MAYUMI, Lia. Taipa, canela-preta e concreto: estudo sobre o restauro de casas bandeiristas. Tese (Doutorado) - Faculdade de Arquitetura e Urbanismo, Universidade de São Paulo, São Paulo, 2005.

MELO, José Evando Vieira de. Café com açúcar: a formação do mercado consumidor de açúcar em São Paulo e o nascimento da grande indústria açucareira paulista na segunda metade do século XIX. Saeculum Revista de História, João Pessoa, n. 14, jan./ jun. 2006.

NORA, P. Entre memória e história: a problemática dos lugares, Projeto História, n. 10, dezembro de 1993 .

PAIVA, Celso Lago. Parecer Técnico CLP-15/2002. Relevância cultural e recomendação de tombamento e conservação a título perene da antiga sede da Fazenda Engenho d'Água. In: FUNDAÇÃO PRÓ-MEMÓRIA DE INDAIATUBA. Processo de tombamento n.01/2002 do imóvel antiga sede da Fazenda Engenho d’Água, localizada na rua Zephiro Puccineli, quadra 38/39, lote s/n, Jardim morada do Sol, Indaiatuba, São Paulo. (Acervo arquivístico do órgão)

Parecer Técnico CLP-22/2002. Relevância Cultural e recomendação de tombamento e conservação a título perene da Casa Número Um. In: FUNDAÇÃO PRÓ-MEMÓRIA DE INDAIATUBA. Processo de tombamento municipal n. 02/2002 referente à preservação da Casa Número Um, localizada na Rua Candelária n.459 (quadra s/n, lote s/n) Centro, Indaiatuba, São Paulo. (Acervo arquivístico do órgão)

Parecer Técnico CLP-26/2002. Relevância Cultural e recomendação de tombamento e conservação a título perene do "Casarão Pau Preto". In: FUNDAÇÃO PRÓ-MEMÓRIA DE INDAIATUBA. Processo de tombamento municipal n. 05/2002 referente à preservação do Casarão Pau Preto de Indaiatuba localizado na Rua Pedro Gonçalves, n. 477 (Quadra s/n, Lote s/n), Jardim Pau Preto, Indaiatuba, São Paulo. (Acervo arquivístico do órgão)

PETRONE, Maria Thereza S. A lavoura canavieira em São Paulo, expansão e declínio (1765-1851). São Paulo: Difusão Europeia do Livro, 1968. 
PUPPI, Marcelo. Modernidade e academia em Lucio Costa: ensaio de historiografia. Revista de História da Arte e Arqueologia, Campinas, n. 1, p. 124-144, 1994.

RODRIGUES, Marly. Imagens do passado: a instituição do patrimônio em São Paulo, 1969-1987. São Paulo: Editora UNESP/IMESP/CONDEPHAAT, 2000.

RUBINO, Silvana. A Memória de Mário. Revista do Patrimônio Histórico e Artístico Nacional, São Paulo, n. 30, p. 138-154, 2002.

SCACHETTI, Ana Ligia. O ofício de compartilhar histórias. Indaiatuba: Fundação PróMemória, 2001.

SAMPAIO, Scyllas Leite de; SAMPAIO, Caio da Costa. Indaiatuba: sua história. Indaiatuba: Rumograf, 1998.

SAIA, Luis. Morada paulista. São Paulo: Perspectiva, 1972.

TOGNON, Marcos. Laudo Técnico Pericial PRO-075-2015. Caracterização das Estruturas Construtivas.Critérios de Preservação. Avaliação do Estado de Preservação. In:. FUNDAÇÃO PRÓ-MEMÓRIA DE INDAIATUBA. Apenso-Processo de tombamento municipal n. 02/2002 referente à preservação da Casa Número Um, localizada na Rua Candelária n.459 (quadra s/n, lote s/n) Centro, Indaiatuba, São Paulo. (Acervo arquivístico do órgão)

ZANETTINI, Paulo E. Maloqueiros e seus palácios de barro: o cotidiano doméstico na casa bandeirista. Tese (Doutorado em Arqueologia) MAE/USP, São Paulo, 2005.

ZOPPI, Antônio. Reminiscências de Indaiatuba. Indaiatuba: Fundação Pró-Memória, 1998. 